\title{
Angiogenic Activity of Sera from Pulmonary Tuberculosis Patients in Relation to IL-12p40 and TNF $\propto$ Serum Levels
}

\author{
Tadeusz M. Zielonka - Urszula Demkow • Dorota Michalowska-Mitczuk • \\ Malgorzata Filewska $\cdot$ Beata Bialas $\cdot$ Katarzyna Zycinska $\cdot$ \\ Michael H. Obrowski · Jan Kus • Ewa Skopinska-Rozewska
}

Received: 2 February 2010/Accepted: 3 April 2011/Published online: 21 May 2011

(C) The Author(s) 2011. This article is published with open access at Springerlink.com

\begin{abstract}
The role of angiogenesis in the pathogenesis of tuberculosis (TB) is not clear. The aim of this study was to examine the effect of sera from TB patients on angiogenesis induced by different subsets of normal human mononuclear cells (MNC) in relation to IL-12p40 and TNF $\alpha$ serum levels. Serum samples from 36 pulmonary TB patients and from 22 healthy volunteers were evaluated. To assess angiogenic reaction the leukocytes-induced angiogenesis test according to Sidky and Auerbach was performed. IL-12p40 and TNF $\alpha$ serum levels were evaluated by ELISA. Sera from TB patients significantly stimulated angiogenic activity of MNC compared to sera from healthy donors and PBS $(p<0.001)$. The number of microvessels formed after injection of lymphocytes preincubated with sera from TB patients was significantly lower compared to the number of microvessels created after injection of MNC preincubated with the same sera $(p<0.016)$. However, the number of microvessels created after the injection of lymphocytes preincubated with sera from healthy donors or with PBS alone was significantly higher $(p<0.017)$. The
\end{abstract}

T. M. Zielonka $(\bowtie) \cdot$ K. Zycinska $\cdot$ M. H. Obrowski Department of Family Medicine, Medical University of Warsaw, Banacha Street 1a, Warsaw 02-097, Poland

e-mail: tmzielonka@wp.pl

U. Demkow

Department of Laboratory Diagnostics and Clinical Immunology of the Developmental Age, Medical University of Warsaw, Warsaw, Poland

D. Michalowska-Mitczuk - M. Filewska - B. Bialas · J. Kus Institute of Tuberculosis and Lung Diseases, Warsaw, Poland

E. Skopinska-Rozewska

Department of Pathology, Biostructure Center, Medical

University of Warsaw, Warsaw, Poland mean levels of IL-12p40 and TNF $\alpha$ were significantly elevated in sera from TB patients compared to healthy donors. We observed a correlation between angiogenic activity of sera from TB patients and IL-12p40 and TNF $\alpha$ serum levels $(p<0.01)$. Sera from TB patients constitute a source of mediators that participate in angiogenesis and prime monocytes for production of proangiogenic factors. The main proangiogenic effect of TB patients' sera is mediated by macrophages/monocytes. TNF $\alpha$ and IL-12p40 may indirectly stimulate angiogenesis in TB.

Keywords Angiogenesis - Tuberculosis - Pathogenesis · Interleukin-12p40 - Tumor necrosis factor alpha

\section{Introduction}

Angiogenesis from preexisting vasculature occurs in many pathological conditions such as tumors [1], cardiovascular diseases [2], chronic inflammation [2, 3], rheumatoid arthritis [4], diabetic retinopathy [5], endometriosis [6], and obesity [7]. In pulmonary nonmalignant diseases angiogenesis has been implicated in the pathogenesis of idiopathic interstitial pneumonia [8], lung fibrosis induced by bleomycin [9], and sarcoidosis [10]. Vascular endothelial growth factor (VEGF) is a fundamental regulator of normal and pathological angiogenesis [11]. Ischemia induces both VEGF production and angiogenesis [12]. Although there have been reports concerning angiogenesis in infectious diseases, its role in the pathogenesis of TB has not been determined [13, 14]. Serum VEGF might be a useful marker as a prognostic indicator in sarcoidosis [15] and other granulomatous diseases, including TB. Increased VEGF levels in serum [16-18], pleural fluid $[19,20]$ and cerebrospinal fluid [21] have been found in 
patients with active TB. VEGF therefore may be associated with the pathogenesis of pulmonary $\mathrm{TB}$ in the development of the chronic inflammatory reaction [18]. M. tuberculosis antigens are considered an important factor participating in the pathogenesis of Eales' disease-an idiopathic retinal periphlebitis characterized by capillary nonperfusion and angiogenesis [22]. In one study, an intense angiogenesis was shown ultrastructurally in active pulmonary tuberculosis lesions [23], but the meaning of this phenomenon is not completely understood yet. An important role in the pathogenesis of TB and also in the modulation of angiogenesis is played by some cytokines, especially IL-12 and TNF $\alpha$ [24-26]. The aim of this study was to examine the effect of sera from TB patients on angiogenesis induced by different subsets of normal human mononuclear cells (MNC) in relation to IL-12p40 and TNF $\alpha$ serum levels.

\section{Materials and Methods}

\section{Study Population}

The study was approved by the local ethics committee. Serum samples were obtained from 36 patients with active pulmonary TB and from 22 healthy volunteers. The TB group consisted of 26 male and 10 female patients aged $49.8 \pm 14.9$ years $($ range $=23-75$ years). All were HIVnegative and 23 were smokers. The diagnosis of pulmonary TB was confirmed by a conventional sputum culture. No systemic or extrapulmonary TB was observed. Blood samples were taken from patients before antituberculosis treatment was started. As a control, sera from 22 healthy nonsmoking volunteers were used (12 women and 10 men, mean age $=38.7 \pm 11.4$, range $=20-58$ years). None of the control volunteers had any past medical history of tuberculosis, other pulmonary diseases, or cancer.

\section{Preparation of Peripheral Blood Mononuclear Cells}

Blood from healthy donors attending the Warsaw Central Blood Bank was collected in a heparinized syringe, then diluted 1:1 in phosphate-buffered saline (PBS) and layered over Lymphoprep separation medium (Sigma). After spinning the tubes for $20 \mathrm{~min}$ at $500 \mathrm{~g}$, the mononuclear fraction was aspirated from the interface. MNC viability estimated by trypan blue stain was $\geq 98 \%$. This method yielded MNC preparation containing 10-15\% monocytes and $85-90 \%$ lymphocytes based on morphologic criteria and myeloperoxidase staining. MNC were depleted of monocytes by glass adherence and phagocytosis of iron particles using $15 \mathrm{mg}$ for $10 \times 10^{6}$ cells.
Leukocyte-induced Angiogenesis Assay (LIA)

To assess the effect of sera from TB patients on angiogenesis induced by different fractions of MNC, a leukocyte-induced angiogenesis test described by Sidky and Auerbach in an animal model [27] with modification [10, 28] was used. The local ethical commission for experimenting on animals approved all procedures involved in this study. Female inbred 8-week-old BALB/c mice served as recipients of MNC or lymphocytes preincubated in PBS supplemented with $25 \%$ of serum from TB patients or from healthy volunteers for $1 \mathrm{~h}$ at $37^{\circ} \mathrm{C}$. As a control, other mice were given MNC or lymphocytes that were preincubated only in PBS. Mice were anesthetized with $3.6 \%$ chloral hydrate (POCH, Poland) and injected intradermally with $5 \times 10^{5}$ cells in Parker liquid (6 injections per mice and 3 mice for each tested patient). The mice were killed after 3 days. The newly formed blood vessels were identified and counted on the inner surface of the skin of each mouse using a microscope (Nikon, Japan) at $6 \times$ magnification. In all cases identification was performed by one expert (UD) based on the previously described criteria [27].

Cytokines

IL-12p40 and TNF $\alpha$ in sera were evaluated by enzymelinked immunosorbent assay (ELISA) using commercially available kits (BIOSOURCE Europe S.A.) according to the manufacturer's instructions. Recombinant TNF $\alpha$ (NIBSC, Hertfordshire, UK, EN6 3 QG) was used as a standard. Concentrations of IL-12p40 in sera were determined by sandwich ELISA using specific IL-12p40 MoAb. Optical density was measured at $450 \mathrm{~nm}$ using spectrophotometric reader Elx800 (Biotek Instruments, Inc., USA).

\section{Statistical Analysis}

The value of the angiogenesis test was expressed as an angiogenesis index $(\mathrm{AI})$ :

$\mathrm{AI}=A_{\mathrm{ex}} / A_{\text {contr }}$

where $A_{\mathrm{ex}}$ is the mean number of micro blood vessels created after the injection of MNC or lymphocytes preincubated in PBS with the serum of a patient or healthy donor, and $A_{\text {contr }}$ is the mean number of micro blood vessels created after the injection of MNC or lymphocytes preincubated with PBS alone

All results are presented as mean \pm SD. Statistical evaluation of the results was performed using Pearson's test, Student's $t$-test, and Mann-Whitney test (Statistica 6 for Windows, Statsoft, Tulsa, OK, USA). A $p$ value $<0.05$ was used to indicate statistical significance. 


\section{Results}

Angiogenic activity of MNC was measured by the mean number of newly formed vessels after injection of MNC preincubated with sera and PBS or with PBS alone. Sera from TB patients significantly indirectly stimulated angiogenesis to a greater extent than sera from healthy donors or PBS alone $(p<0.001)$ (Fig. 1). Proangiogenic activity of sera from TB patients (mean number of microvessels $=16.9 \pm 0.9$ ) was significantly higher than that of sera from healthy donors (13.99 \pm 0.73 vessels; $p<0.001)$. However, sera from healthy donors also significantly $(p<0.001)$ stimulated angiogenic activity of normal MNC compared to MNC preincubated only with PBS (12.7 \pm 1.16 vessels).

Following the injection of lymphocytes preincubated with sera from $20 \mathrm{~TB}$ patients, the mean number of microvessels significantly decreased $(16 \pm 1.33 ; p<0.05)$ compared to the number of microvessels after the injection of a full suspension of MNC preincubated with the same sera (17 \pm 0.79$)$ (Fig. 2a). However, the mean number of microvessels after injection of lymphocytes preincubated with sera from healthy donors significantly increased (from $13.99 \pm 0.73$ to $14.8 \pm 1.0 ; p<0.01)$ compared to the number of microvessels after the injection of a full suspension of MNC preincubated with the same sera (Fig. 2b). A similar effect was observed in the control group when MNC or lymphocytes were preincubated with PBS alone (increase from $12.7 \pm 1.16$ to $13.8 \pm 1.63 ; p<0.05$ ) (Fig. 2c). The results were expressed as an angiogenic index and the following relationships were observed: After injection of MNC preincubated with sera from TB patients, AI was $1.29 \pm 0.03$ but it significantly decreased $(1.12 \pm 0.09 ; p<0.001)$ following preincubation of lymphocytes with sera from TB patients. However, following the injection of lymphocytes preincubated with sera from healthy volunteers, AI remained the same as after the injection of MNC preincubated with sera from healthy volunteers $(1.06 \pm 0.04$ vs. $1.07 \pm 0.06)$.

The IL-12p40 serum level was significantly elevated in TB patients $(355 \pm 279 \mathrm{pg} / \mathrm{ml} ; p<0.01)$ compared to that of healthy controls (64 $\pm 70 \mathrm{pg} / \mathrm{ml})$ (Fig. 3a). A significant correlation was found between the IL-12p40 serum level and angiogenic properties of sera of the examined patients and healthy donors $(r=0.57, p<0.01)$ (Fig. 4a). $\mathrm{TNF} \alpha$ serum level from $\mathrm{TB}$ patients $(31 \pm 8 \mathrm{pg} / \mathrm{ml}$; $p<0.002$ ) was significantly elevated compared to that of healthy controls $(21 \pm 3.4 \mathrm{pg} / \mathrm{ml})$ (Fig. 3b). A significant
Fig. 1 Mean number of new vessels after injection of MNC preincubated with sera from TB patients $(n=36)$, sera from healthy controls $(n=22)$, and PBS $(n=22)$. The means are indicated by horizontal bars
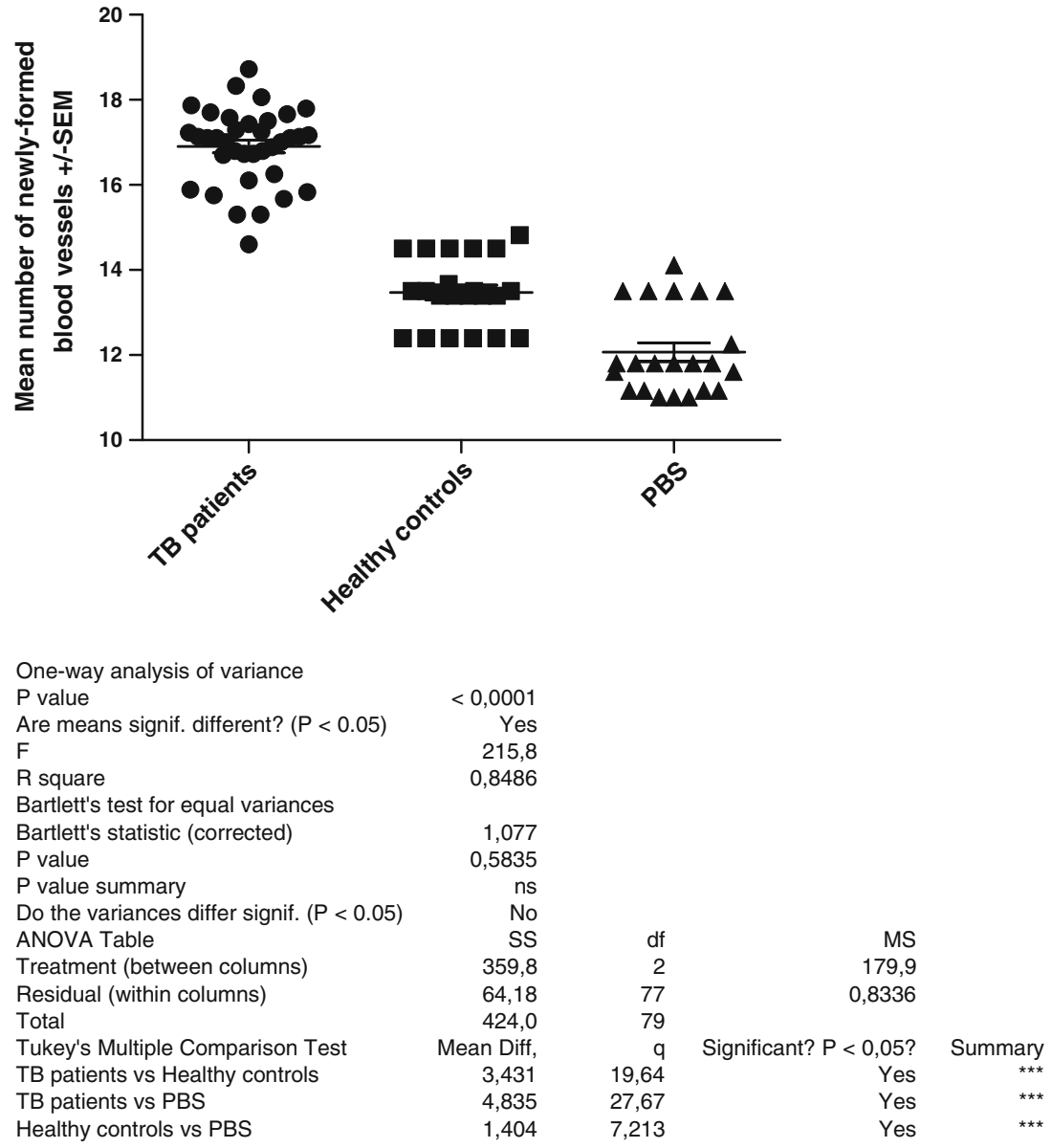

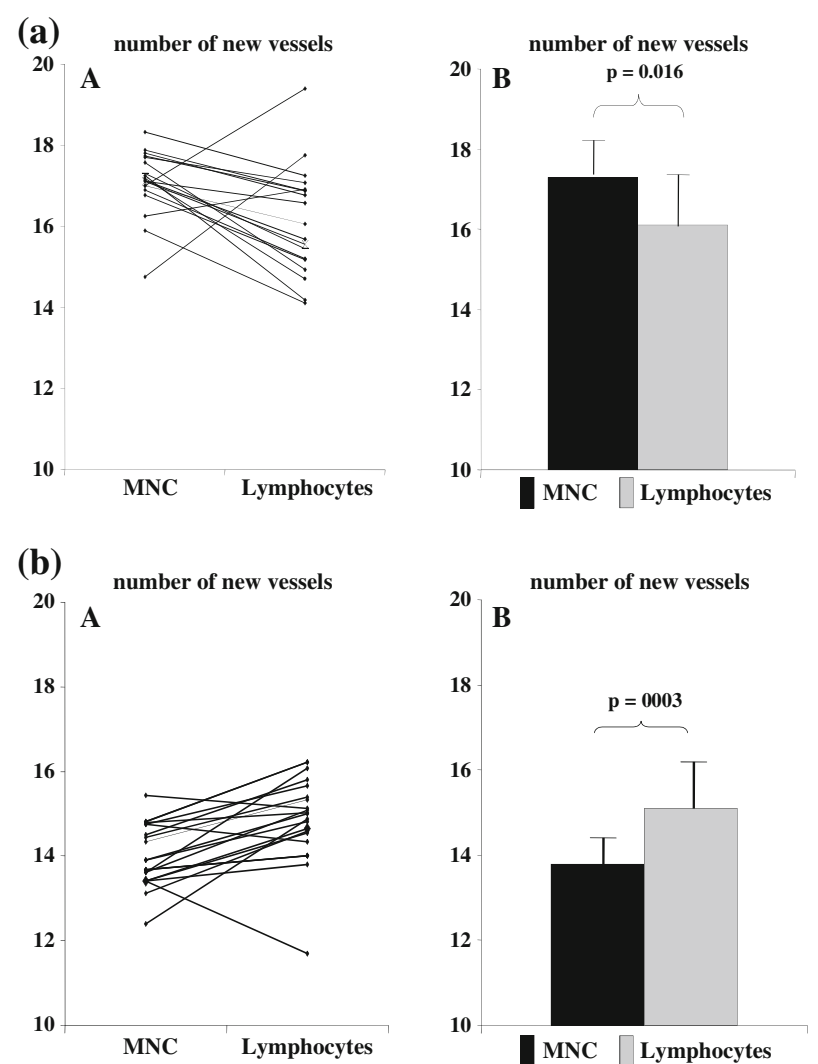

(c)
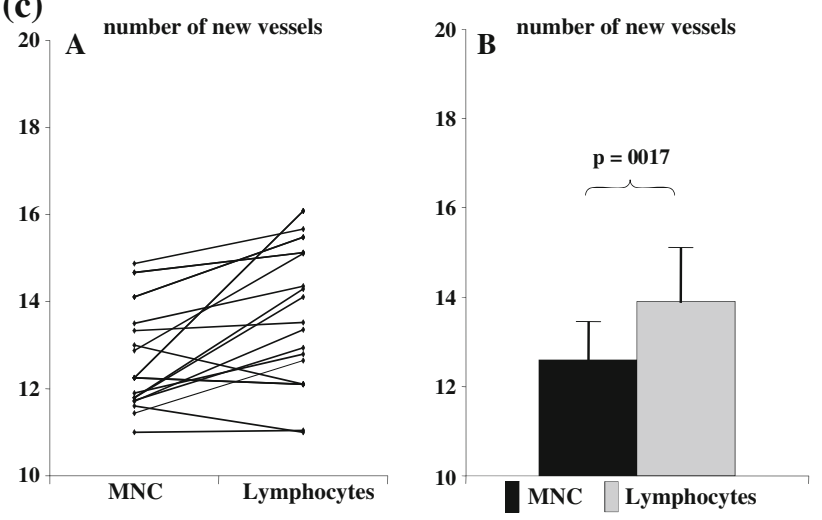

Fig. 2 Mean number of new vessels after injection of MNC and lymphocytes preincubated in the same time (A, individual results; B, mean result). a With sera from TB patients $(n=20)$. b With sera from healthy donors $(n=22)$. c Without sera (only in PBS as a control) $(n=22)$

correlation $(r=0.62, p<0.01)$ between TNF $\alpha$ serum level and angiogenic activity of sera was found (Fig. 4b).

\section{Discussion}

These results confirm suggestions $[16,17]$ of the involvement of angiogenesis in TB. The positive correlation between angiogenic activity measured by the number of

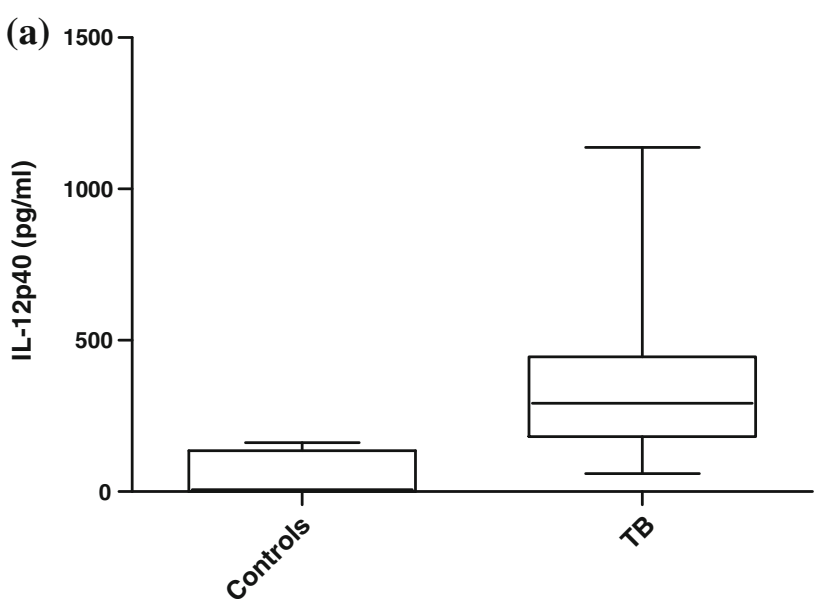

Mann Whitney test

$P$ value

Exact or approximate $P$ value?

One- or two-tailed $P$ value?

Sum of ranks in column A,B
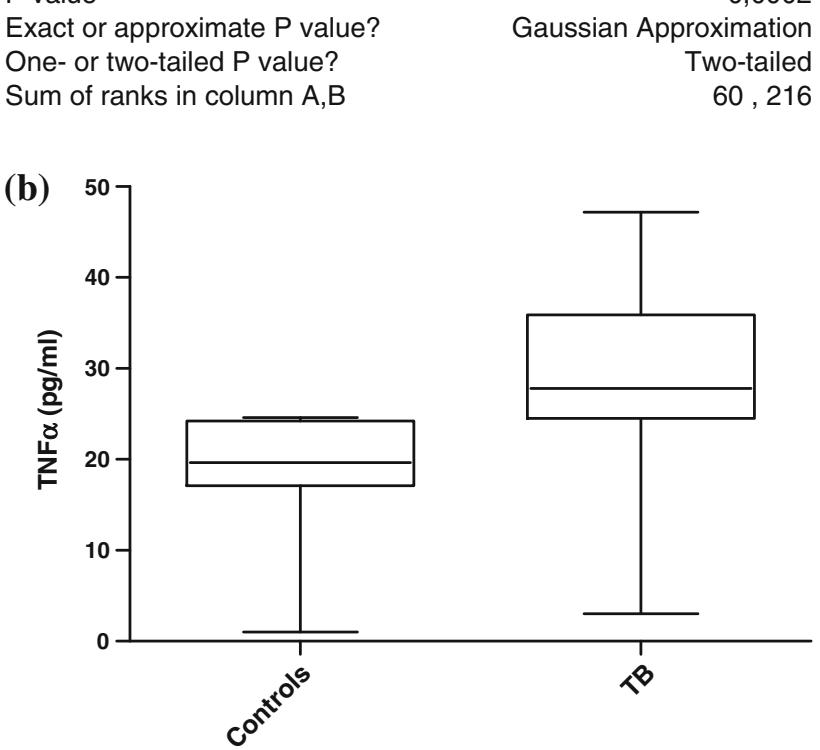

Mann Whitney test

$P$ value

0,0021

Exact or approximate $P$ value?

Are medians signif. different? $(P<0.05)$

Sum of ranks in column $A, B$

Gaussian Approximation

Yes

70,206

Fig. 3 a IL-12p40 serum level from patients with TB $(n=13)$ and from healthy controls $(n=10)$. b TNF $\alpha$ serum level from patients with TB $(n=12)$ and from healthy controls $(n=9)$

newly created vessels after the injection of MNC preincubated with sera of TB patients and IL-12p40 and TNF $\alpha$ serum concentration levels seems to suggest that these cytokines play an important role in the pathogenesis of the neovascularization [29, 30]. Our previous studies carried out on the same model did not confirm any correlation between angiogenic activity of sarcoidosis patients' sera and IL- 6 and IL-8 serum levels [10]. However, TNF $\alpha$, an important proinflammatory factor, may stimulate angiogenesis in interstitial lung diseases, and a weak correlation was observed between the serum level of IL-12 and the 

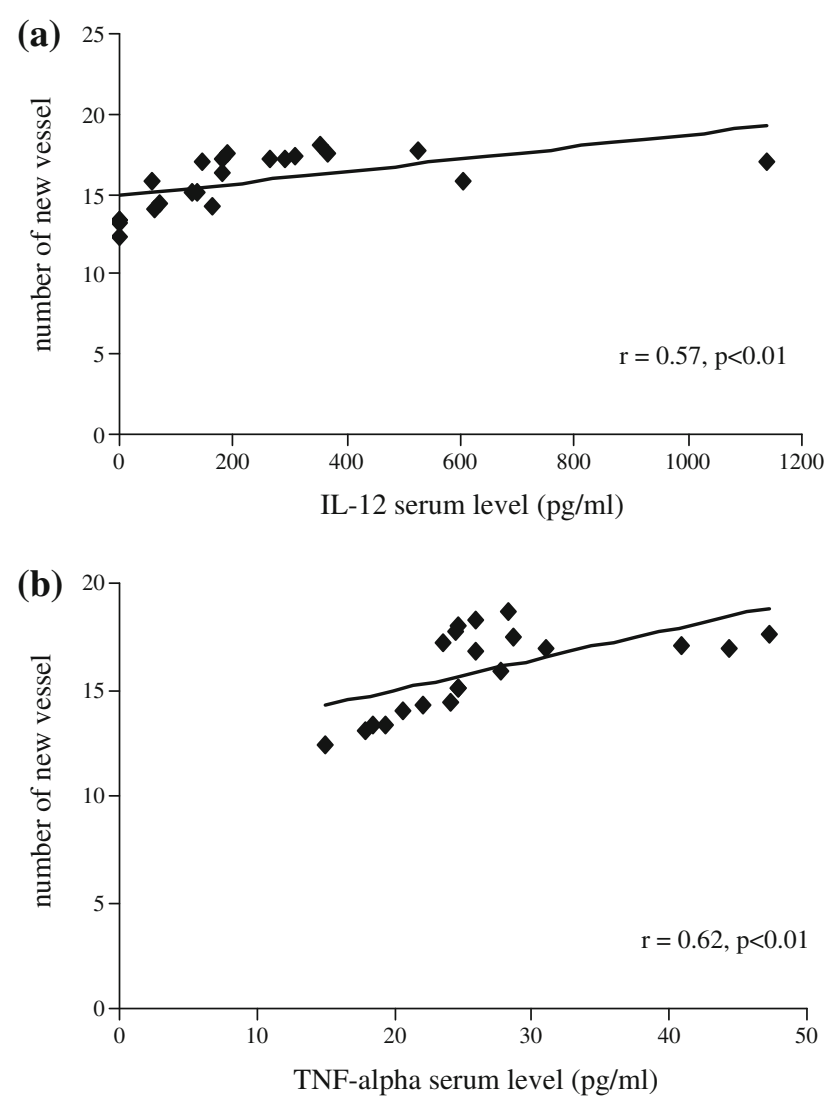

Fig. 4 a Correlation between angiogenic activity of sera from TB patients $(n=13)$ or from healthy controls $(n=10)$ and IL-12p40 serum level. b Correlation between angiogenic activity of sera from TB patients $(n=12)$ or from healthy controls $(n=9)$ and TNF $\alpha$ serum level ( $r=$ Pearson's coefficient)

number of new vessels created after intradermal injection of MNC preincubated with sera from interstitial lung diseases patients [31, 32]. Our results support the hypothesis about the possible link between angiogenic activity of TB patients' sera and IL-12 and TNF $\alpha$. These cytokines, which play an important role in the pathogenesis of $\mathrm{TB}$, also modulate angiogenesis $[25,26,29,30]$. Significant correlations between the concentration of these cytokines and radiological findings in TB patients were found [24]. Some reports point to neovascularization in the pathogenesis of tuberculosis. Thus, Abe et al. [16] suggest that the increased blood vessel formation and oxygen supply caused by the overexpression of VEGF inhibits cavity formation in TB. However, studies of Alatas et al. [17] did not confirm these findings. These authors observed a significant increase of VEGF serum level in active TB, and a decrease with effective antituberculosis treatment [17]. Matsuyama et al. [18] reported higher VEGF levels in the sera of patients with active pulmonary TB. Mycobacterium tuberculosis-infected monocytes develop a matrix-degrading phenotype [33]. Matrix degradation is the essential first step in the process of creating new vessels from the preexisting vasculature. In $\mathrm{TB}$ meningitis, monocytes secrete matrix metalloproteinase-9, which facilitates leukocyte migration across the blood-brain barrier [34]. TNF $\alpha$ plays an important role in this process as well [33]. Lipoarabinomannan, one of the main $M$ tuberculosis antigens, stimulates macrophages to release metalloproteinase-9, which, by breaking down proteins, not only causes formation of cavities but also induces angiogenesis [35]. A correlation between VEGF and TNF $\alpha$ was also observed in the pathogenesis of exudate in tuberculous pleuritis [20]. TNF $\alpha$ is produced by various cells in the inflammatory site and induces angiogenic cytokines, including IL-8, VEGF, and basic fibroblast growth factor (bFGF), all of which are involved in neovascularization [36]. Saita et al. [37] demonstrated that intracorneal challenge with trehalose 6,6'-dimycolate derived from $M$ tuberculosis induces an inflammatory response, including granuloma formation and neovascularization. The angiogenic reaction was inhibited by neutralizing antibodies targeting VEGF and IL-8, partially by anti-TNF $\alpha$ antibodies, but not by anti-IL-1 $\beta$ [37]. Macrophages stimulated with cord factor produce proinflammatory type-1 helper-T-cell-inducing cytokines, including TNF $\alpha$, IL-1, chemotactic factors, and IL-12 [38]. In time it leads to the increase of VEGF concentration [38].

Establishing the key role of the monocytes in inducing angiogenic activity when affected by sera of TB patients is an important result of this study. The angiogenic effect of TB patients' sera was different than that of sera from healthy donors. Healthy human sera stimulated stronger lymphocytes than monocytes. In the case of TB patients, depletion of monocytes from MNC decreased the proangiogenic effect of the sera; therefore, the proangiogenic factors present in the patients' sera stimulated mainly monocytes and had no such strong effect on lymphocytes. From this observation we may conclude that the main proangiogenic effect of TB patients' sera is mediated by macrophages/monocytes. Matsuyama et al. [18] showed by immunohistochemistry that the expression of VEGF occurred in the alveolar macrophages around active TB lesions. It has been demonstrated that VEGF plays a role in the pathogenesis of pulmonary $M$ avium complex infection [39]. Therefore, it can be assumed that activated macrophages are the main cells that secrete VEGF in TB lesions when affected by factors such as IL-12 and TNF $\alpha$. Pulmonary TB and sarcoidosis are granulomatous diseases and their pathogenesis has been linked to monocytes and alveolar macrophages [40, 41]. Meyer et al. [42] pointed out the key role of monocytes from sarcoidosis patients in stimulating neovascularization. In an earlier study we also demonstrated that sera from sarcoidosis patients prime monocytes for production of proangiogenic factors [10]. Sakaguchi et al. [43] indicated that trehalose 6,6'-dimycolate augments VEGF production by neutrophils and 
macrophages and induces neovascularization in granulomatous tissue. Chronic inflammation in TB is characterized by a localized accumulation of mononuclear cells, i.e., the formation of a granuloma that is surrounded by neovascularization [41]. Angiogenesis is required for the progression of chronic inflammation [3].

IL-12 is a multifunctional cytokine produced by macrophages and dendritic cells. As a factor promoting the commitment of naïve lymphocytes to a $\mathrm{Th}_{1}$-type profile of cytokine expression, IL-12 may be pivotal in the cascade of proinflammatory events in the lungs [44]. The number of cells expressing $\mathrm{Th}_{1}$-type cytokines such as INF $\gamma$ and IL-12 is increased within the lungs of patients with granulomatous disease such as TB and sarcoidosis [29]. IL-12 not only stimulates the growth of $\mathrm{T}$ and NK cells but also inhibits angiogenesis in solid tumors [45]. IL-12 is a heterodimeric cytokine composed of p40 and p34 chains. The subunit of IL-12p40 is in a free form, which blocks specific receptors to stimulate angiogenesis; this determined the selection of this cytokine for this study. Heterodimeric IL-12 and free p40 were present in tuberculous pleural effusions but not in malignant pleural effusions, suggesting that IL-12 is produced in the local immune response to infection [46]. Cooper et al. [47] have demonstrated that IL-12p40 knockout mice are defective in their ability to induce INF $\gamma$ production and to generate a protective $\mathrm{Th}_{1}$-type of immunologic response in TB. IL-12 proved to be an effective and successful adjuvant to a standard treatment in patients suffering from progressive clinical TB [48].

It is difficult to determine whether neovascularization plays a beneficial or a harmful role in the course of TB. It can only be assumed that the growth of a localized inflammatory mass requires neovascularization. Insufficient angiogenesis resulting in hypoxia creates favorable conditions for tissue necrosis and cavity formation. Therefore, further research on neovascularization and its role in the pathogenesis of TB is necessary.

\section{Conclusions}

Sera from TB patients constitute a source of mediators participating in angiogenesis. Sera from TB patients prime monocytes for production of proangiogenic factors. TNF $\alpha$ and IL-12p40 as important proinflammatory factors may stimulate angiogenesis in TB.

Open Access This article is distributed under the terms of the Creative Commons Attribution Noncommercial License which permits any noncommercial use, distribution, and reproduction in any medium, provided the original author(s) and source are credited.

\section{References}

1. Carmeliet P, Jain RK (2000) Angiogenesis in cancer and other diseases. Nature 407:249-257

2. Griffioen AW, Molema G (2000) Angiogenesis: potentials for pharmacologic intervention in the treatment of cancer, cardiovascular diseases, and chronic inflammation. Pharmacol Rev $52: 237-368$

3. Jackson JR, Seed MP, Kircher CH, Willoughby DA, Winkler JD (1997) The codependence of angiogenesis and chronic inflammation. FASEB J 11:457-465

4. Firestein GS (1999) Starving the synovium: angiogenesis and inflammation in rheumatoid arthritis. J Clin Invest 103:3-4

5. Smith LE, Shen W, Perruzzi C, Soker S, Kinose F, Xu X, Robinson G, Driver S, Bischoff J, Zhang B, Schaeffer JM, Senger DR (1999) Regulation of vascular endothelial growth factor-dependent retinal neovascularisation by insulin-like growth factor-1 receptor. Nat Med 5:1390-1395

6. Rogers PA, Gargett CE (1998) Endometrial angiogenesis. Angiogenesis 2:287-294

7. Crandall DL, Hausman GJ, Kral JG (1997) A review of the microcirculation of adipose tissue: anatomic, metabolic, and angiogenic perspectives. Microcirculation 4:211-232

8. Simler NR, Brenchley PE, Horrocks AW, Greaves SM, Hasleton PS, Egan JJ (2004) Angiogenic cytokines in patients with idiopathic interstitial pneumonia. Thorax 59:581-585

9. Burdick MD, Murray LA, Keane MP, Xue YY, Zisman DA, Belperio JA, Strieter RM (2005) CXCL11 attenuates bleomycininduced pulmonary fibrosis via inhibition of vascular remodeling. Am J Respir Crit Care Med 171:261-268

10. Zielonka TM, Demkow U, Białas B, Filewska M, Zycinska K, Radzikowska E, Szopiński J, Skopińska-Rózewska E (2007) Modulatory effect of sera from sarcoidosis patients on mononuclear cells-induced angiogenesis. J Physiol Pharmacol 58(Suppl 5): 753-766

11. Shibuya M (2001) Structure and function of VEGF/VEGFreceptor system involved in angiogenesis. Cell Struct Funct 26:25-35

12. Keane MP, Strieter RM (2002) The importance of balanced proinflammatory and anti-inflammatory mechanisms in diffuse lung disease. Respir Res 3:5-11

13. Kraft A, Weindel K, Ochs A, Marth C, Zmija J, Schumacher P, Unger C, Marmé D, Gastl G (1999) Vascular endothelial growth factor in the sera and effusions of patients with malignant and nonmalignant disease. Cancer 85:178-187

14. Mittermayer F, Pleiner J, Schaller G, Weltermann A, Kapiotis S, Jilma B, Wolzt M (2003) Marked increase in vascular endothelial growth factor concentrations during Escherichia coli endotoxininduced acute inflammation in humans. Eur J Clin Invest 33: 758-761

15. Sekiya M, Ohwada A, Miura K, Takahashi S, Fukuchi Y (2003) Serum vascular endothelial growth factor as a possible prognostic indicator in sarcoidosis. Lung 181:259-265

16. Abe Y, Nakamura M, Oshika Y, Hatanaka H, Tokunaga T, Ohkubo Y, Hashizume T, Suzuki K, Fujino T (2001) Serum levels of vascular endothelial growth factor and cavity formation in active pulmonary tuberculosis. Respiration 68:496-500

17. Alatas F, Alatas O, Metintas M, Ozarslan A, Erginel S, Yildirim H (2004) Vascular endothelial growth factor levels in active pulmonary tuberculosis. Chest 125:2156-2159

18. Matsuyama W, Hashiguchi T, Matsumuro K, Iwami F, Hirotsu Y, Kawabata M, Arimura K, Osame M (2000) Increased serum levels of vascular endothelial growth factor in pulmonary tuberculosis. Am J Respir Crit Care Med 162:1120-1122 
19. Kiropoulos TS, Kostikas K, Gourgoulianis KI (2005) Vascular endothelial growth factor levels in pleural fluid and serum of patients with tuberculous pleural effusions. Chest 128:468-469

20. Hamed EA, El-Noweihi AM, Mohamed AZ, Mahmoud A (2004) Vasoactive mediators (VEGF and TNF-alpha) in patients with malignant and tuberculous pleural effusions. Respirology 9: $81-86$

21. Matsuyama W, Hashiguchi T, Umehara F, Matsuura E, Kawabata M, Arimura K, Maruyama I, Osame M (2001) Expression of vascular endothelial growth factor in tuberculous meningitis. J Neurol Sci 186:75-79

22. Ramakrishnan S, Rajesh M, Sulochana KN (2007) Eales' disease: oxidant stress and weak antioxidant defence. Indian J Ophthalmol 55:95-102

23. Ridley MJ, Heather CJ, Brown I, Willoughby DA (1983) Experimental epithelioid cell granulomas, tubercle formation and immunological competence: an ultrastructural analysis. J Pathol 141:97-112

24. Casarini M, Ameglio F, Alemanno L, Zangrilli P, Mattia P, Paone G, Bisetti A, Giosuè S (1999) Cytokine levels correlate with a radiologic score in active pulmonary tuberculosis. Am J Respir Crit Care Med 159:143-148

25. Brion ChA, Gazzinelli RT (1995) Effect of IL-12 on immune responses to microbial infections: a key mediator in regulating diseases outcome. Curr Opin Immunol 7:485-496

26. Bergron A, Bonay M, Kambouchner M, Lecossier D, Riquet M, Soler P, Hance A, Tazi A (1997) Cytokine patterns in tuberculous and sarcoid granulomas. J Immunol 159:3034-3043

27. Sidky YA, Auerbach R (1975) Lymphocyte-induced angiogenesis: a quantitative and sensitive assay for the graft-versus-host reaction. J Exp Med 141:1084-1100

28. Zielonka TM, Demkow U, Filewska M, Bialas B, Zycinska K, Radzikowska E, Wardyn AK, Skopinska-Rozewska E (2010) Angiogenic activity of sera from extrinsic allergic alveolitis patients in relation to clinical, radiological, and functional pulmonary changes. Lung 188:375-380

29. Taha RA, Minshall EM, Olivenstein R, Ihaku D, Wallaert B, Tsicopoulos A, Tonnel AB, Damia R, Menzies D, Hamid QA (1999) Increased expression of Il-12 receptor mRNA in active pulmonary tuberculosis and sarcoidosis. Am J Respir Crit Care Med 160:1119-1123

30. Selvaraj P, Sriram U, Mathan Kurian S, Reetha AM, Narayanan PR (2001) Tumour necrosis factor alpha ( -238 and -308$)$ and beta gene polymorphisms in pulmonary tuberculosis: haplotype analysis with HLA-A, B and DR genes. Tuberculosis 81:335-341

31. Zielonka TM, Demkow U, Filewska M, Bialas B, Korczynski P, Szopinski J, Soszka A, Skopinska-Rozewska E (2007) Angiogenic activity of sera from interstitial lung diseases patients to IL-6, IL-8, IL-12 and TNF $\alpha$ serum level. Centr Eur J Immunol 32:53-60

32. Zielonka TM, Demkow U, Puscinska E, Golian-Geremek A, Filewska M, Zycinska K, Bialas-Chromiec B, Wardyn KA, Skopinska-Rozewska E (2007) TNFalpha and INFgamma inducing capacity of sera from patients with interstitial lung disease in relation to its angiogenesis activity. J Physiol Pharmacol 58(Suppl 5):767-780

33. Duan L, Gan H, Arm J, Remold HG (2001) Cytosolic phospholipase A2 participates with $\mathrm{TNF} \alpha$ in the induction of human macrophages infected with Mycobacterium tuberculosis H37Ra. J Immunol 166:7469-7476
34. Price NM, Farrar J, Tran TT, Nguyen TH, Tran TH, Friedland JS (2001) Identification of a matrix-degrading phenotype in human tuberculosis in vitro and in vivo. J Immunol 166:4223-4230

35. Chang JC, Wysocki A, Tchou-Wang KM, Moskowitz N, Zhang Y, Rom WN (1996) Effect of Mycobacterium tuberculosis and its components on macrophages and the release of matrix metalloproteinases. Thorax 51:306-311

36. Yoshida S, Ono M, Shono T, Izumi H, Ishibashi T, Suzuki H, Kuwano M (1997) Involvement of interleukin-8, vascular endothelial growth factor, and basic fibroblast growth factor in tumor necrosis factor alpha-dependent angiogenesis. Mol Cell Biol 17:4015-4023

37. Saita N, Fujiwara N, Yano I, Soejima K, Kobayashi K (2000) Trehalose 6,6'-dimycolate (cord factor) of Mycobacterium tuberculosis induces corneal angiogenesis in rats. Infect Immun 68:5991-5997

38. Oswald IP, Dozois CM, Petit JF, Lemaire G (1997) Interleukin12 synthesis is a required step in trehalose dimycolate-induced activation of mouse peritoneal macrophages. Infect Immun 65:1364-1369

39. Nishigaki Y, Fujiuchi S, Fujita Y, Yamazaki Y, Sato M, Yamamoto Y, Takeda A, Fujikane T, Shimizu T, Kikuchi K (2006) Increased serum level of vascular endothelial growth factor in Mycobacterium avium complex infection. Respirology 11:407-413

40. Müller-Quernheim J (1998) Sarcoidosis: immunopathogenic concepts and their clinical application. Eur Respir J 12:716-738

41. Kobayashi K, Yoshida T (1996) The immunopathogenesis of granulomatous inflammation induced by Mycobacterium tuberculosis. Methods 9:204-214

42. Meyer KC, Kaminski MJ, Calhoun WJ, Auerbach R (1989) Studies of bronchoalveolar lavage cells and fluids in pulmonary sarcoidosis. I. Enhanced capacity of bronchoalveolar lavage cells from patients with pulmonary sarcoidosis to induce angiogenesis in vivo. Am Rev Respir Dis 140:1446-1449

43. Sakaguchi I, Ikeda N, Nakayama M, Kato Y, Yano I, Kaneda K (2000) Trehalose 6,6'-dimycolate (cord factor) enhances neovascularization through vascular endothelial growth factor production by neutrophils and macrophages. Infect Immun 68:2043-2052

44. Manetti R, Parronchi P, Giudizi MG, Piccinni MP, Maggi E, Trinchieri G, Romagnani S (1993) Natural killer cell stimulatory factor (IL-12) induces $\mathrm{T}$ helper type (Th1) specific immune responses and inhibits the development of IL-4 producing Th cells. J Exp Med 177:1199-1204

45. Duda DG, Sunamura M, Lozonschi L, Kodama T, Egawa S, Matsumoto G, Shimamura H, Shibuya K, Takeda K, Matsuno S (2000) Direct in vitro evidence and in vivo analysis of the antiangiogenesis effects of interleukin 12. Cancer Res 60:1111-1116

46. Zhang M, Gately MK, Wang E, Gong J, Wolf SF, Lu S, Modlin RL, Barnes PF (1994) Interleukin 12 at the site of disease in tuberculosis. J Clin Invest 93:1733-1739

47. Cooper AM, Magram J, Ferrante J, Orme IM (1997) Interleukin 12 (IL-12) is crucial to the development of protective immunity in mice intravenously infected with Mycobacterium tuberculosis. J Exp Med 186:39-45

48. Greinert U, Ernst M, Schlaak M, Entzian P (2001) Interleukin-12 as successful adjuvant in tuberculosis treatment. Eur Respir $\mathrm{J}$ 17:1049-1051 